\title{
Differences in nurses' knowledge, behavior and patient falls incidents and severity following a falls e-learning program
}

\author{
Maree Johnson ${ }^{1}$, Neil Hime ${ }^{2}$, Catherine Zheng ${ }^{2}$, Duong Thuy $\operatorname{Tran}^{3}$, Linda Kelly ${ }^{4}$, Katica Siric ${ }^{5}$ \\ 1. School of Nursing \& Midwifery, Centre for Applied Nursing Research, South Western Sydney Local Health District \& \\ University of Western Sydney, Locked Bag, Australia. 2. Centre for Applied Nursing Research, South Western Sydney Local \\ Health District, Sydney, Australia. 3. School of Medicine, University of Western Sydney, Sydney, Australia. 4. Centre for \\ Education \& Workforce Development, Sydney Local Health District, Sydney, Australia. 5. Concord Repatriation General \\ Hospital, Sydney Local Health District, Sydney, Australia.
}

Correspondence: Maree J ohnson. Address: University of Western Sydney, School of Nursing \& Midwifery, Locked Bag 1797, Penrith, NSW, 2751, Australia. Email: m.johnson@uws.edu.au

Received: August 1, 2013

DOI : $10.5430 /$ jnep.v4n4p28
Accepted: September 23, 2013 Online Published: November 27, 2013

URL: http://dx.doi.org/10.5430/jnep.v4n4p28

\section{Abstract}

Background: Continuing high rates of falls was a major concern to senior nurses within our health service. Researchers and educators came together to develop and evaluate an on-line falls e-learning program to increase nurses' knowledge and falls prevention behaviors and therefore reduce falls incidents and severity.

Methods: Using a pre-post test design, nurses' knowledge and behaviour $(\mathrm{N}=71)$ were measured prior to undertaking the education program and three months after, using the Nurses' Falls Knowledge Test and the Falls-Prevent Scale. Patient falls incidents and severity were compared for 8 months prior to and 8 months following completion of the education program.

Results: Falls knowledge was high at pre (20/21 correct) and post testing $(20)$ with no significant difference $(P=.24)$ found. Falls prevention behaviors significantly increased from 198.5 pre-test to 211 post-test $(P<.001)$. There was no change in rates of falls (mean falls rates per 1000 occupied bed days [OBD] were 8.9 pre and 8.8 post, hospital $1 ; 3.5$ pre and 5.5 post; hospital 2). A reduction in the severity of falls occurred in hospital 1 but the changes were too small for significance testing.

Conclusions: This e-learning falls education program has demonstrated increases in nurses' preventive falls behaviors. Although falls incidents were not reduced the best practice approaches promoted by this program are supported in national health policy and some systematic reviews. This program is being distributed to our hospitals.

\section{Key words}

Falls education, E-learning, Nursing

\section{I ntroduction}

With the increasing proportion of patients aged 65 years and older presenting to acute health services, the incidence of falls related injury has been increasing, ranging between 3 and 14 per 1000 bed days ${ }^{[1]}$. A fall has been defined 'an unexpected 
event in which the participants come to rest on the ground, floor, or lower level' (p. 1619) ${ }^{[2]}$. Falls injuries can result in considerable morbidity and mortality in the elderly and substantial health costs ${ }^{[3]}$. A recent national study of hospitals in England and Wales found that $32 \%$ of all patient incidents were related to falls ${ }^{[1]}$. Falls prevention or minimisation has become a priority for all health professionals, but the major role of prevention, post-fall management, and reporting of falls incidents remains with nursing ${ }^{[4]}$.

Best practice guidelines ${ }^{[5]}$ and systematic reviews ${ }^{[6]}$ have defined a number of preventative behaviors for patients requiring promotion by nurses ${ }^{[5]}$. In addition, there are also defined interventions for nurses to minimise the opportunity for patient falls within the hospital environment ${ }^{[7]}$. The Falls Committee of our local health service, sought to reduce the incidence and severity of falls in hospitalised patients by implementing a pilot study of an e-learning program on falls prevention for nursing staff. Aspects of the evaluation of this e-learning program have been reported (Johnson et al., under review) with data collected through health care record audits and observation. We found that the program resulted in improvements in identification of falls risk and prevention strategies, including falls risk flagging within records and on beds, supervision of the patient when mobilizing or in the bathroom, areas clear of hazards, and referrals to allied health staff. This paper further reports on nurses' self-reported knowledge, behavior and falls incidents and severity before and after the e-learning program.

Systematic reviews of multifactorial ${ }^{[8,9]}$ and single falls prevention interventions, have demonstrated reductions in falls in acute settings or within the community ${ }^{[10,11]}$. However, some large cluster randomised trials have also reported no effects of interventions within acute settings ${ }^{[12]}$. Oliver et. al. ${ }^{[13]}$ emphasised that in some clinical areas, for example rehabilitation, the achievement of higher levels of physical functioning and mobility indicates increased risk of falls, referred to as 'unpreventable' falls (p. 328). Although large trials targeting acute inpatients continue to address this serious patient safety issue $^{[12]}$, nurses can engage in several behaviors that have the potential to minimise falls or to reduce the severity of injury. A randomised controlled trial using a falls education intervention (of 8 hours duration) given to 374 registered nurses did find an improvement in falls knowledge. This trial did not examine how knowledge changed behaviour or how knowledge improvement impacted of patient falls ${ }^{[14]}$. We hypothesised that by improving nurses' knowledge and falls prevention behaviors, there would be a reduction in patient falls incidents and severity. The following hypothesised were examined:

i) There would be an increase in nurses' knowledge and falls prevention behavior, following completion of the Falls E-learning Education Program;

ii) There would be a reduction in the rate and severity of patient falls, following nurses' completion of the Falls E-learning Education Program.

\section{Methods}

A pre-test and post-test comparative design ${ }^{[15]}$ was used. Over a study period of 20 months, data were collected related to falls incidents and severity for a period of 8 months (pre) (March 2010 to October 2010) and a further 8 months period (post) (March 2011 to October 2011). Nurses accessed the e-learning education program from November 2010 to February 2011 (a period of 4 months). Measurement of nurses' knowledge occurred prior to completing the education program online (knowledge) and then again in hardcopy at three months post education. Nurses' falls prevention behavior was measured prior to completing the education program and then three months post education using a hardcopy survey.

\section{Sample and setting}

Hospitals were selected with a high intake of elderly patients (mean age of 80 years or older) and a high rate of falls ( $>4$ per 1000 occupied bed days). Two subacute Sydney hospitals specialising in aged care participated in the study. Hospital 1 had four wards with 92 inpatient beds and hospital 2 had one ward with 36 inpatient beds. All nurses working in these hospitals were invited to participate (63 hospital 1; 37 hospital 2). 
Table 1. Characteristics of 71 Nurses Participating in the Surveys

\begin{tabular}{|c|c|c|}
\hline & No. (\%) & $\begin{array}{l}\text { Mean } \pm \text { SD } \\
\text { (range) }\end{array}$ \\
\hline \multicolumn{3}{|l|}{ Gender } \\
\hline Female & $54(78)$ & \\
\hline Male & $15(22)$ & \\
\hline Age (years) & & $\begin{array}{l}41.7 \pm 10.4 \\
(22-60)\end{array}$ \\
\hline $\begin{array}{l}\text { Employment designation } \\
\text { Registered nurse } \\
\text { Enrolled nurse } \\
\text { Assistant in nursing } \\
\text { Nurse unit manager } \\
\text { Clinical nurse specialist }\end{array}$ & $\begin{array}{l}39(55) \\
19(27) \\
7(10) \\
5(7) \\
1(1)\end{array}$ & \\
\hline \multicolumn{3}{|l|}{ Employment status } \\
\hline Permanent full-time & $50(70)$ & \\
\hline Permanent part-time & $15(21)$ & \\
\hline Casual & $6(9)$ & \\
\hline \multicolumn{3}{|l|}{ Highest level of education } \\
\hline Bachelors Degree & 27 (39) & \\
\hline Hospital Certificate & $13(19)$ & \\
\hline Other & $9(13)$ & \\
\hline Diploma & $7(10)$ & \\
\hline Graduate Certificate & $6(9)$ & \\
\hline Graduate Diploma & $4(6)$ & \\
\hline Masters Degree & $4(6)$ & \\
\hline Total length of time practising as a nurse (years) & & $\begin{array}{l}15.3 \pm 10.3 \\
(0.7-38.0)\end{array}$ \\
\hline Length of time working in current ward/unit (years) & & $\begin{array}{l}6.4 \pm 5.6 \\
(0.04-22.0)\end{array}$ \\
\hline \multicolumn{3}{|l|}{ Have received specific training in falls management: } \\
\hline Yes & $34(49)$ & \\
\hline No & $36(51)$ & \\
\hline \multicolumn{3}{|l|}{ If Yes, the last falls management training was: } \\
\hline in the last 2 years & $24(71)$ & \\
\hline $2-5$ years ago & $9(27)$ & \\
\hline more than 5 years ago & $1(3)$ & \\
\hline
\end{tabular}

Note. Some nurses did not complete some items. Percentage totals more than $100 \%$ are due to rounding decimals.

\section{Survey participants}

Seventy-one nurses (50, hospital 1 [79\%]; 21, hospital 2 [56\%]) participated in the study with a mean age of 41.7 years ( $\mathrm{SD}=10.4$, range 22 to 60 years) (see Table1). The majority of participants were registered nurses (55\%) or enrolled [licensed practical nurses] nurses (27\%), working full-time (70\%). Nurses had been practising for an average of 15.3 years (SD = 10.3 years) (see Table 1). Seventy per cent of the nurses were university educated. Half of the nurses had not previously received specific training in falls management. Among those who received falls training, $71 \%$ completed the training in the last two years. Most nurses were requested to complete the program by their manager (67\%).

This study was approved by the Human Research and Ethics Committee of the Concord Repatriation General Hospital, South Western Sydney Area Health Service, as a quality assurance project Approval No. CH62/6/2010-054.

\section{I ntervention: E-learning education program}

The intervention included a 60-minute e-learning program, delivering four key elements of the Falls Policy including falls risk screening, prevention strategies, post-fall assessment and management procedures, documentation and accountability of falls-related clinical issues ${ }^{[16]}$. Prevention strategies reflected multifactorial approaches to falls prevention promoted by current systematic reviews and best practice guidelines including: use of alert signs, supervision of patients when toileting 
or using bathroom, placing mobility aids within reach, keeping bed height low, medication review, use of hip protectors, and providing clear access ${ }^{[7,8]}$. Nurses accessed the program from November 2010 to February 2011 (although it remained open until May 2011) through established cost centres for each area using their staff identification numbers. Nurses were able to access the program as many times as they wished during the accessible period.

\section{Outcome measures}

The levels of nurses' knowledge were measured by the Nurses' Falls Knowledge Test (NFKT) parallel forms Part A (pre-test, immediately prior to the education program) and Part B (three months after). Each Part contains 21 items which were either true/false or multiple choice questions addressing three major domains: assessment of patients for fall risk, fall prevention strategies and post-fall management. The NFKT parallel form A and form B has been piloted in a sample of 166 registered nurses from our local health service with a Spearman Brown coefficient of .616 and no differences in scores of each domain and total scores, confirming equivalence of parallel forms ${ }^{[18]}$. An example of an item is 'Antihypertensive drug therapy can increase falls risk, true or false'. A copy of the NFKT is available upon request.

The self-reported fall prevention behaviors were measured by the Falls-Prevent Scale, which rates the frequency of nurses practising 27 behavioral tasks on an eight-point scale $(1=$ never to $8=$ always). This scale contains 2 factors (Falls Prevention Strategies and Post Fall Management) and has demonstrated content validity, construct validity (explaining $70 \%$ of the variance in the underlying construct), and internal consistency (of .85 and .84 for Factors 1 and 2 and .75 for the entire scale) (unpublished data). An example of an item from the scale is 'I ensure the pathway from the bed to the bathroom area is clear of clutter'. The Falls-Prevent Scale was paper-based and self-administered and was distributed to the nurses for completion prior to the e-learning education and three months after. A copy of the Falls-Prevent Scale is available upon request.

Falls incidents and severity data were extracted from the local health service's Incident Information Management System (IIMS) database for the participating hospitals pre, during and following the implementation of the e-learning program. Staff log an incident (such as a fall) within an electronic incident reporting system and include details of the incident. Severity of the fall incidents was rated using the Safety Assessment Code (SAC) matrix: SAC1 (extreme), SAC2 (major/moderate), SAC3 (moderate/minor), and SAC4 (minor/insignificant) ${ }^{[19]}$. The number of falls for patients within the hospitals and the occupied bed days of each month were recorded for a period of 20 months between March 2010 and October 2011.

\section{Data analysis}

Mann-Whitney U tests were performed to compare scores of nurses' knowledge and behavior between the pre-and post-test as data were not normally distributed requiring the use of non-parametric procedures. The Statistical Package for the Social Sciences (SPSS) for Windows version 21.0 (SPSS Inc., Chicago, IL, USA) was used. The number of falls and severity (SAC 1, 2, 3, and 4) and the occupied bed days of each month were calculated. Quasi-Poisson regression models for count data with a log link function ${ }^{[20,21]}$ were built to calculate the rates of falls per 1000 occupied bed days (OBD). R version 3.0.0 ${ }^{[22]}$ and the effects package version 2.2-4 were used ${ }^{[23]}$. Rates of falls differed significantly between the two hospitals $(P<.001)$. Hence, rates and severity of falls were analysed for each hospital separately.

\section{Results}

\section{Nurses' falls knowledge}

Of 21 questions the median correctly answered was 20 pre and 20 post-education (see Table 2) reflecting very high knowledge scores at the two time points. No statistically significant effect on nurse's knowledge of assessment of patients for fall risk, fall prevention strategies and post-fall management was found (see Table 2). 


\section{Nurses' falls prevention behaviors}

Despite the education program having minimal effect on nurse's knowledge, it did result in behavioral changes. The median total response score for 27 behaviors was 198.5 pre-education and 211 post-education $(P<.001$, see Table 2), representing an increase in prevention behaviors. Fourteen of the 27 behaviors show a statistically significant improvement on the 1 to 8 response score scale and none show a worsening of behavior (data not shown). The majority of this behavioral improvement relates to Prevention strategies (median total score pre-education 42 versus 48 post-education, $P$ $<.001)$.

Table 2. Results of the Nurses’ Falls Knowledge Test (NFKT) and Falls-Prevent Scale of the nurse's survey Pre- and Three Months Post-delivery of the Falls E-learning Education Program

\begin{tabular}{|c|c|c|c|}
\hline & Pre-education & Post-education & $P^{*}$ \\
\hline \multicolumn{4}{|l|}{ NFKT } \\
\hline \multirow[t]{2}{*}{ Number of nurses } & 35 & 43 & \\
\hline & Median score & & \\
\hline Risk assessment (7 items) & 7 & 6 & .009 \\
\hline Prevention (8 items) & 8 & 8 & .931 \\
\hline Post Fall Management (6 items) & 6 & 6 & .431 \\
\hline Total (21 items) & 20 & 20 & .187 \\
\hline \multicolumn{4}{|l|}{ Falls-Prevent Scale } \\
\hline \multirow[t]{2}{*}{ Number of nurses } & 36 & 38 & \\
\hline & Median score & & \\
\hline Prevention Strategies(6 items) & 42 & 48 & $<.001$ \\
\hline Post Fall Management (2 items) & 16 & $16^{\#}$ & .047 \\
\hline Total (27 items) & 198.5 & 211 & $<.001$ \\
\hline
\end{tabular}

Notes. ${ }^{*}$ Mann-Whitney U test. ${ }^{*}$ pre mean 14.63 (SD 1.95) median 16; post mean 15.48 (SD 1.06), median 16, (unpaired $t$-test, t value-2.496, $p=.14$ )
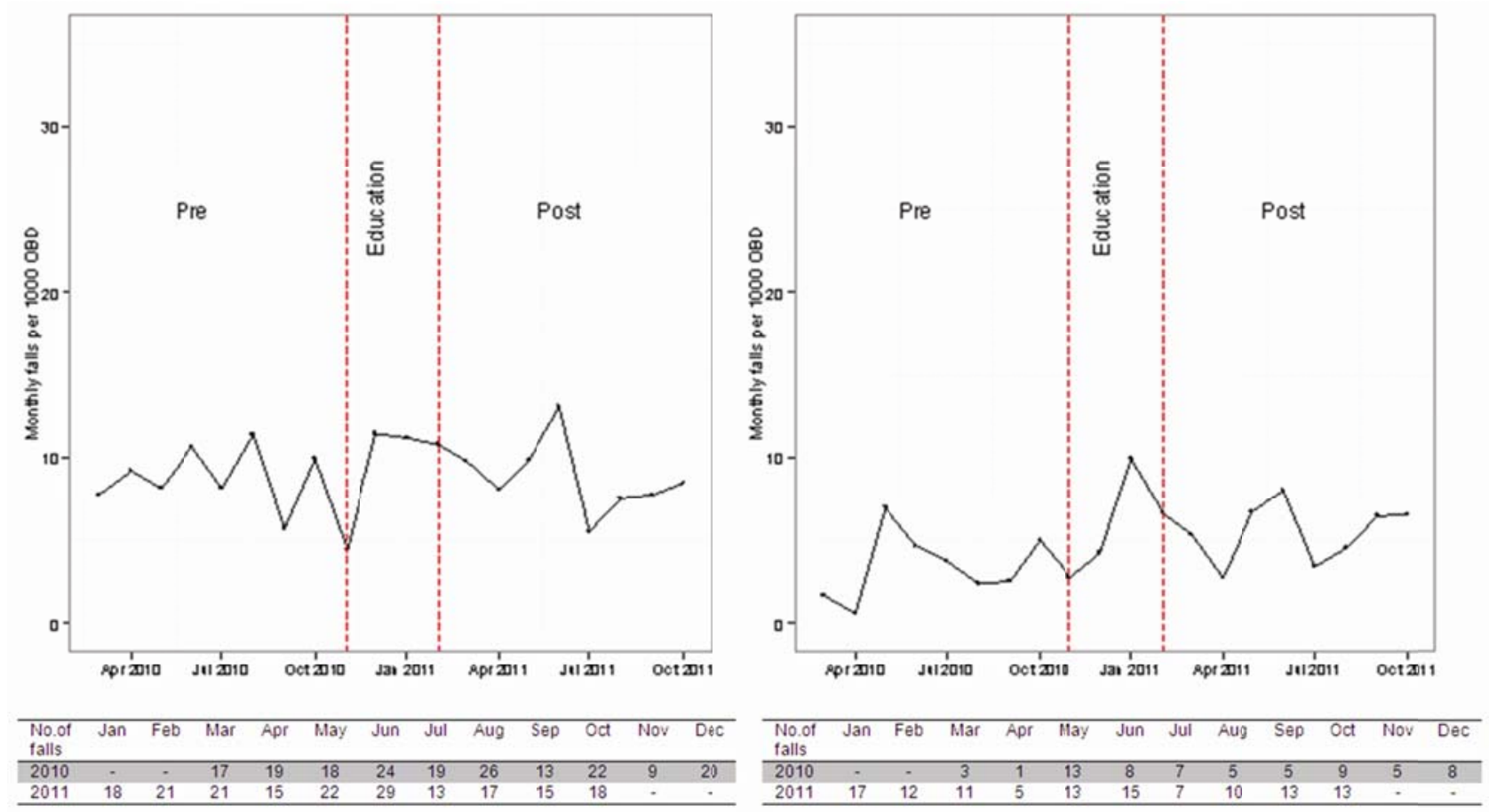

Figure 1. Monthly falls rate per 1000 OBD with crude number of falls (table) for each hospital. Education occurred from November 2010 to February 2011 


\section{Patient falls incidents}

In total, 376 falls occurred in hospital 1 and 180 falls occurred in hospital 2 during the 20-month period (see Figure 1). For hospital 1 , the total number of falls was 158 pre-education and 150 post-education. The mean fall rates per 1000 OBD were 8.9 (95\% CI 7.4 to 10.7) pre, 9.3 (95\% CI 7.0 to 12.4) during education and 8.8 (95\% CI 7.2 to 10.6) post-education. There was no significant difference in the fall rates between pre and post-education $(P=.9)$.

For hospital 2, the total number of falls was 51 pre-education and 87 post-education. The mean fall rates per 1000 OBD was 3.5 (95\% CI 2.3 to 5.2) pre-education, 5.8 (95\% CI 3.7 to 9.1) during education and 5.5 (95\% CI 4.0 to 7.5 ) post-education. There was an upward trend in fall rates from pre-education to post-education, but this was not significant at the 0.05 level $(P=.07)$ (see Figure 2).

Figure 2 gives the effect plot for the e-learning program on each hospital, which shows clearly different patterns for these two hospitals. For the effect plot demonstrated, a 95-percent point-wise confidence interval is drawn around the estimated effect.

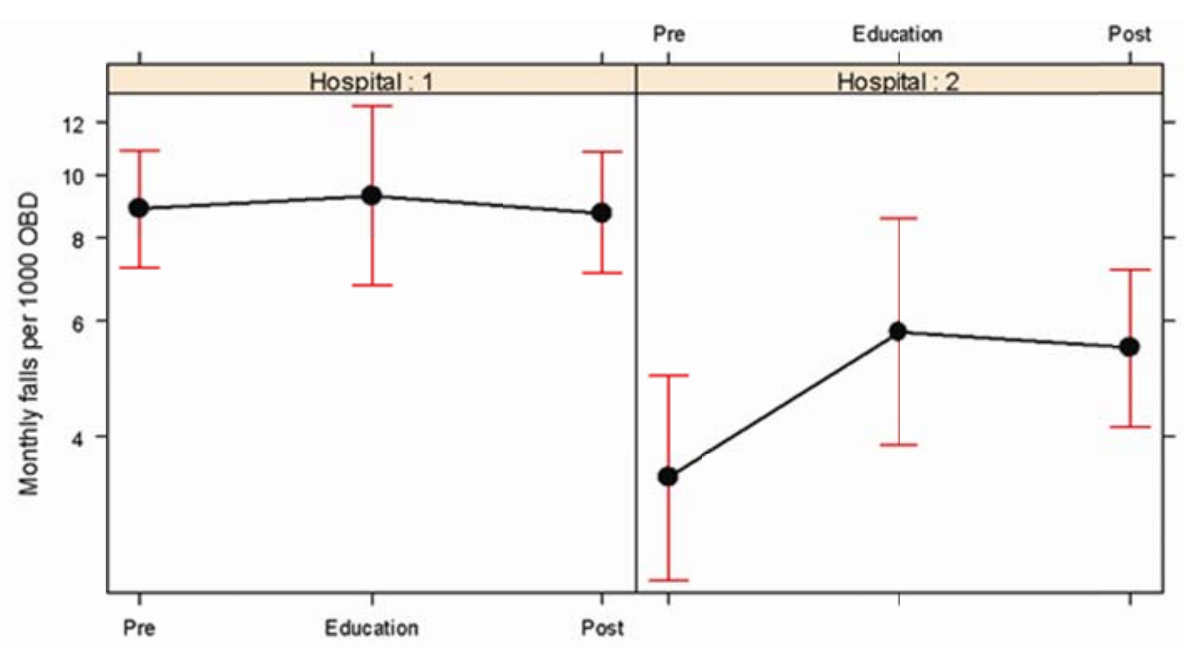

Figure 2. Effect plot for the education program and two hospitals. Pre refers to the period from March 2010 to October 2010; education refers to the period from November 2010 to February 2011; post refers to the period from March 2011 to October 2011

\section{Falls severity}

In hospital 1, no SAC1 falls were recorded. The total number of falls classified as SAC2 (major/moderate) was 6 pre-education and 1 post-education. There was no significant difference in either the SAC3 falls rates or SAC 4 falls rates between the pre-education and post-education periods (SAC3 $P=.5$; SAC4 $P=.8$ ). In hospital 2, no SAC1 or SAC2 falls were recorded during the study period. There was an upward trend in the SAC3 fall rates from pre-education to post-education $(P=.04)$, but no significant difference was found in SAC4 fall rates $(P=.9)$.

\section{Discussion}

In this study we have proposed that improvements in nurses' knowledge and falls prevention behavior following an on-line falls education program, will be associated with reductions in patient falls incidents and severity. Nurses in this study demonstrated high levels of knowledge which remained unchanged, improved falls prevention behaviors, but no reduction in patient falls incidents or severity was found. Although there is a plethora of guidelines and policies relating to falls reduction strategies, clinical trials have found varying results ${ }^{[24]}$, with a recent systematic review confirming the effectiveness of multifactorial interventions in acute settings ${ }^{[25]}$, while other systematic reviews within acute and chronic 
settings report no conclusive evidence ${ }^{[8]}$. One cluster randomised trial in nursing homes (similar patients to this study) in Sweden did demonstrate reductions in falls ${ }^{[26]}$. Even though falls incidents were not reduced in this study, nurses still need to deliver best practice in falls prevention given the available evidence.

\section{Knowledge}

The levels of nurses' knowledge were high initially and no differences in levels of knowledge were found pre-education and post-education. In this study we also found that $50 \%$ of the nurses had undertaken training in falls education within the past two years, which may of contributed to the high knowledge level present in this sample. In a study by Liu et al. ${ }^{\text {[14] }}$ nurses' falls knowledge increased and remained high at the three month level. Although most knowledge items in this study were correctly answered, further education on using the risk screening tool, and how medications influenced the risk of falls is recommended.

\section{Behavior}

Considerable behavioral change was found in this study. Of the 27 behavioral actions assessed, 14 were improved following the education. Using the internally consistent factor structure of the Falls-Prevent Scale, a significant improvement in strategies to prevent falls $(P<.001)$ and also changes to post-fall management practices $(P<.05)$ were demonstrated. These data do suggest an improvement in falls prevention behaviors. It has been suggested that checking of staff compliance with these behaviors should be regularly undertaken ${ }^{[27]}$, and the Falls-Prevent Scale provides a suitable tool.

\section{Falls incidents and severity}

The analysis of the data highlighted that the two hospitals differed in their frequency of falls and severity of falls, although the characteristics of patients (mean age, falls screening risk severity score of possible fallers) in the hospitals during the study period were similar. Hospital 1 had falls incidents with a SAC of 2, 3 and 4, while hospital 2 had falls incidents with a SAC of 3 or 4 only. For hospital 1, there was no evidence of an effect of the e-learning program on the mean fall rates. Within the severity data, the total number of falls classified as SAC2 was reduced from 6 (pre) to 1 (post) during the period from March to October (suggesting some improvement although significance testing was not possible due to the small numbers). The SAC2 rating reflects major or moderate harm and therefore this effect is worthy of note. In hospital 2, the mean fall rate at pre-education appeared to be lower than those at education and post-education, although not statistically significant. In this hospital, there was no SAC1 or SAC2 falls. This may reflect increased reporting of near misses with an increased number of incidents within the minor or insignificant category. Repeated education sessions on falls may be of benefit for nurses to remain vigilant over time ${ }^{[14]}$.

The incident data reported here includes patients who are 'near misses' that is no injury occurs and the fall is prevented, although we believe that this would represent a small number of falls. Further discussions are occurring with the incident system designers to capture and separate 'near misses' and also to identify patients who are repeat fallers. Some authors also suggest that given nurses find most fallen patients ${ }^{[28]}$ nurses should ask the patient: '... have you had any fall including a slip or trip in which you lost your balance and landed on the floor or ground or lower level' and this question should be part of the definitions within a falls incident system ${ }^{[2]}$.

This study is the first Australian study to pilot test comprehensively the effectiveness of an e-learning falls education program on changing nurses' knowledge, behavior and falls incidents and severity within some limitations in design. Studies conducted in increased numbers of wards and/or over extended periods of time (three years or more) will refute or confirm these findings ${ }^{[29]}$. Data relating to confounding factors such as nurse to patient ratios and skill mix were not collected. This information has an important effect on falls incidents ${ }^{[30]}$. In this study $71 \%$ of nurses (79\% in hospital 1 and $56 \%$ in hospital 2) completed the education program with 29\% not participating, which may have influenced these findings. Self-reporting of behaviors was undertaken which may result in under or over-reporting of behaviors. Changes in the patient characteristics throughout the study period (pre versus post) were not examined and may of influenced the 
number or severity of falls. For example an increased number of frail aged patients could potentially greatly increase the incidents and severity of falls. This pilot study did not use randomisation or concurrent control groups. Further studies using cluster randomised controlled trials, are required to confirm or refute these findings, such trials were beyond the available funding. Matching of staff data on knowledge and behavior although attempted in this study resulted in too small of a matched sample to be useful.

For educators and managers the focus of these findings should remain on increasing falls prevention behaviors based on the best available evidence and this education program has achieved this outcome. Continuing research in very large samples will provide further evidence of the effectiveness of targeted or standardised multifactorial approaches, as advocated in this e-learning program. Although falls reductions were not demonstrated in this limited sample, continued support for best practice relating to falls prevention is advocated. The distribution of this program within New South Wales hospitals is underway.

\section{Conclusions}

This e-learning education program has demonstrated increases in preventive falls behaviors by nurses with no direct reduction in falls or the severity of falls. Nonetheless, nurses should be encouraged to use the multifactorial approaches found effective based on the best available evidence, as found in this e-learning program. Monitoring of behavioral changes using the Falls-Prevent Scale and falls incident and severity data is recommended. Continued vigilance from managers, educators and patient safety co-ordinators, is required to mitigate patient fall risk or injury severity wherever possible.

\section{References}

[1] Healy F, Treml J. Changes in falls prevention policies in hospital in England and Wales. Age Ageing. 2013; $42: 106-9$. PMid:22572240 http://dx.doi.org/10.1093/ageing/afs063

[2] Lamb SE, Jorstad-Stein EC, Hauer K, Becker C. Development of a common outcome data set for fall injury prevention trials: the prevention of Falls Network Europe consensus. Journal of the American Geriatrics Society. 2005; 53: 1618-22. PMid:16137297 http://dx.doi.org/10.1111/j.1532-5415.2005.53455.x

[3] Grol R, Grimshaw J. From best evidence to best practice: effective implementation of change in patients' care. The Lancet. 2003; 361: 1225-30.

[4] Tzeng HM, Yin CY. The extrinsic risk factors for inpatient falls in hospital patient rooms. Journal of Nursing Care Quality. 2008; 23: 233-41. PMid:18562866 http://dx.doi.org/10.1097/01.NCQ.0000324588.91837.84

[5] Australian Commission on Safety and Quality in Health Care. Implementation Guide for Preventing Falls and Harm From Falls in Older People: Best Practice Guidelines for Australian Hospitals and Residential Aged Care Facilities. 2009.

[6] Chang JT, Morton SC, Rubenstein LZ, et al. Interventions for the prevention of falls in older adults: Systematic review and meta-analysis of randomised clinical trials. British Medical Journal. 2004; 328: 680-3. PMid:15031239 http://dx.doi.org/10.1136/bmj.328.7441.680

[7] Falls Prevention Strategies. Clinical Excellence Commission, 2009. (Accessed 15 July, 2010, http://www.cec.health.nsw.gov.au/files/falls-prevention/resources/falls_strategies.pdf.)

[8] Coussement J, dePaepe L, SChwendimann R, Denhareynck K, Dejaeger E, Milisen K. Interventions for Preventing Falls in Acuteand Chronic- Care Hospitals: a systematc review and meta-analysis. Journal of the American Geriatrics Society. 2008; 56: 29-36. PMid:18031484 http://dx.doi.org/10.1111/j.1532-5415.2007.01508.x

[9] Salminen MJ, Vahlberg TJ, Salonoja MT, Aarnio PTT, Kivela SL. Effect of a risk-based multifactorial fall prevention program on the incidence of falls. Journal of the American Geriatrics Society. 2009; 57: 612-9. PMid:19392952

http://dx.doi.org/10.1111/j.1532-5415.2009.02176.x

[10] Sherrington C, Whitney TC, Lord SR, Herbert RD, Cumming RG, Close JC. Effective exercise for the prevention of falls: a systematic review and meta-analysis. Journal of the American Geriatrics Society. 2008; 56: 2234-43. PMid:19093923 http://dx.doi.org/10.1111/j.1532-5415.2008.02014.x 
[11] Clemson L, Cumming RG, Kendig H, Swann M, Heard R, Taylor K. The effectiveness of a community-based program for reducing the incidence of falls in the elderly: a randomized trial. J Am Geriatr Soc. 2004; 52: 1487-94. PMid:15341550 http://dx.doi.org/10.1111/j.1532-5415.2004.52411.x

[12] Cumming RG, Sherrington C, Lord SR, et al. Cluster randomised trial of a targeted multifactorial intervention to prevent falls among older people in hospital. BMJ. 2008; 336: 758-60. PMid:18332052 http://dx.doi.org/10.1136/bmj.39499.546030.BE

[13] Oliver D. Prevention of falls in hospital inpatients. Agendas for research and practice. Age and Ageing. 2004; 33: 328-30. PMid:15226103 http://dx.doi.org/10.1093/ageing/afh145

[14] Liu H, Shen J, Xiao LDX. Effectiveness of an educational intervention on improving knowledge level of Chinese registered nurses on prevention of falls in hospitalized older people--A randomized controlled trial. Nurse Education Today. 2012 ; 32: 695-702. PMid:22051103 http://dx.doi.org/10.1016/j.nedt.2011.09.009

[15] Jirojwong S, Johnson M, Welch A, eds. Research Methods in Nursing \& Midwifery. Pathways to Evidence-based Practice. Melbourne: Oxford University Press.; 2011.

[16] Johnson M, Kelly L, Siric K, Overs B. Falls E-Learning Programme for Nursing Education. Australian Nursing Journal. 2012; Feb 19: 37.

[17] Barker A, Kamar J, Morton A, Berlowitz D. Bridging the gap between research and practice: review of a targeted hospital inpatient fall prevention programme. Qual Saf Health Care. 2009; 18: 467-72. PMid:19955459 http://dx.doi.org/10.1136/qshc.2007.025676

[18] Johnson M, Tran D, Siric K., Kelly L. Development of a Nurses' Falls Knowledge Test. Presented at the 8th Australasian Association for Quality in Health Care (AAQHC) Conference, 8-9 September 2010, Perth 2010.

[19] NSW Department of Health and the Clinical Excellence Commission. Incident management in the NSW public health system. 2008: January to June. Sydney; 2009.

[20] Nelder JA, Wedderburn RWM. Generalized Linear Models. Journal of the Royal Statistical Society Series A (General). 1972; 135: 370-84. http://dx.doi.org/10.2307/2344614

[21] McCullagh P, Nelder JA. Generalized linear models. Second edition. New York, USA: Chapman and Hall. 1989.

[22] R: A Language and Environment for Statistical Computing. R Foundation for Statistical Computing, 2013. (Accessed at http://www.R-project.org.)

[23] Fox J. Effect Displays in R for Generalised Linear Models. Journal of Statistical Software. 2003; 8: 1-27.

[24] Stern C, Jayasekara R. Interventions to reduce the incidence of falls in older adult patients in acute care hospitals: a systematic review. International Journal of Evidence Based Healthcare. 2009; 7: 243-9. PMid:21631865 http://dx.doi.org/10.1111/j.1744-1609.2009.00143.x

[25] Cameron ID, Gillespie LD, Robertson MC, et al. Interventions for preventing falls in older people in care facilities and hospitals (Review). Cochrance Database Systematic Review. 2012; Dec 12:12:CD005465.

[26] Neyens JC, Dijcks BP, Twisk J, et al. A multifactorial intervention for the prevention of falls in psychogeriatric nursing home patients, a randomised controlled trial (RCT). Age Ageing. 2009; 38: 194-9. PMid:19221130 http://dx.doi.org/10.1093/ageing/afn297

[27] Ohde S, Terai M, Oizumi A, et al. The effectiveness of a multidisciplinary QI activity for accidental fall prevention: Staff compliance is critical. BMC Health Service Research. 2012; 12: 197-204. PMid:22788785 http://dx.doi.org/10.1186/1472-6963-12-197

[28] Johnson M, George A, Tran DT. Analysis of falls incidents: nurse and patient preventative behaviours. International Journal of Nursing Practice. 2011; 17: 60-6. PMid:21251155 http://dx.doi.org/10.1111/j.1440-172X.2010.01907.x

[29] Barker A, Brand C, Haines T, et al. The 6-PACK programme to decrease fall-related injuries in acute hopsitals: protocol for a cluster randomised controlled trial. Injury Prevention. 2013; 17: e5.

[30] Dunton N, Gajewski B, Taunton R, Moore J. Nurse staffing and patient falls on acute care hospital units. Nursing Outlook. 2004; 52: 53-9. PMid:15014380 http://dx.doi.org/10.1016/j.outlook.2003.11.006 